\title{
Growing Epidemic of Obesity, A Challenge that Requires Environmental Modifications Obezogjenik and Lifelong Critical Elements
}

\author{
Elida PEKA ${ }^{1}$, Dr Enver ROSHI ${ }^{2}$, Jolanda ZOGA ${ }^{2}$, Englantina ZOGA ${ }^{2}$, Fatime ZOGA ${ }^{2}$ \\ ${ }^{1}$ Lecturer Faculty of Technical Medical Sciences, Medical University of Tirana \\ ${ }^{2}$ Professor, Dean Faculty of Public Health, Tirana \\ ${ }^{3}$ Teknicient Laboratory, the Service of Genetics, University Hospital Center \\ ${ }^{4}$ Specialist, I relations with the public sector, Tirana \\ ${ }^{5}$ Specialist, I relations with the public sector, Tirana
}

\begin{abstract}
The prevalence of childhood overweight has increased substantially in many countries during recent decades ${ }^{[1,2]}$. In Europe and other developed countries, the prevalence of overweight seems to be especially high among children in lower social groups ${ }^{22-3]}$. The prevalence of overweight is steadily increasing among children and adolescents. Previous studies showed that the rate of overweight in the United States had more than doubled in children and tripled in adolescents during the previous 30 years. In 2010, the prevalence of obesity among children and adolescents exceeded $30 \% .{ }^{[4-5] .}$.The alarming increase in the prevalence of overweight may adversely affect physical and psychosocial health among children and adolescents and increase the risk of adult obesity. ${ }^{[6]}$. Childhood obesity is a complex problem with various factors involved; genetics, environmental factors, parenting style and family's health behaviours e.g. parents' and children's diet, physical activity and sedentary habits ${ }^{[-\underline{-8}]}$. Increased understanding of the substantial influence of genetic, epigenetic, social, and environmental factors in childhood and adolescence has highlighted the importance of parental characteristics. Children living with overweight parents, especially mothers, are more likely to become overweight. ${ }^{[9-10]}$. Children are vulnerable to the social and environmental pressures that raise the risk of obesity ${ }^{[11]}$. Clearly, parents affect dietary and activity patterns, particularly among preschoolers and young children, which, ultimately, can impact child weight status' [12-13-14]. Grocery behaviors directly conditioned by a cultural model in which they are inserted and applied. Characteristics of parents considered today as determining factors in the pathology of obesity in children aged developing. Based on these considerations, our study also included several socioeconomic variables of the families of children in the study. (Table 1.1) They were invited to complete questionnaires from 520 parents who agreed to cooperate 484 parents as follows.
\end{abstract}

Keywords: obesity, overweight, prevalence, nutrion, children, school, city, vilage, Tirana

\section{The Aim of the Study}

Assessment of nutritional status of a group of children aged 11-13-15 years old district of Tirana (overweight and obesity)

Objective I: Evaluation of correlation prevalence of children with socio-economic status of households relative.

Objective II: Collection of information on food habits and the factors influencing food choices, through an anonymous questionnaire completed by parents.

\section{The Research Methodology}

Type of study is transversal. This type of research is used because these types of studies directly assess the severity of risk factors in the population. We attempted to do an assessment of socio-economic factors that influence food choices in the family, through information received from the parents of these children. They invited all the parents of the children selected for the collection of this information from the survey who agreed to meet 484 of them or $93 \%$ of them. Standardized questionnaires were translated and adapted. To design the questionnaire relied on the experience of INRA
(Instituto Nazionale di Ricerca per gli Alimenti of Nutrizione, Rome, Italy). Parents questionnaire contained questions aimed at collecting a greenhouse data on: Family: weight, height, age, education level, occupation of parents. Child, breastfeeding, his physical activity, qualitative aspects and frequency of food consumption, food preferences, etc. Diet and health: sources of information about nutrition, food preparation and family who, etc. Finally perception of body image of their child by the parents.

Statistical analysis: The analysis was conducted with the help of statistical package SPSS 20.0 and M.Office.Excel 2010.

Table 1.1: Some socio-economic variables of the families of the children in the study

\begin{tabular}{|lc|}
\hline \multicolumn{2}{|c|}{ Who complements the questionnaire } \\
Mother & $71.1 \%$ \\
Father & $27.9 \%$ \\
Other & $1.0 \%$ \\
Total & $100 \%$ \\
\hline
\end{tabular}




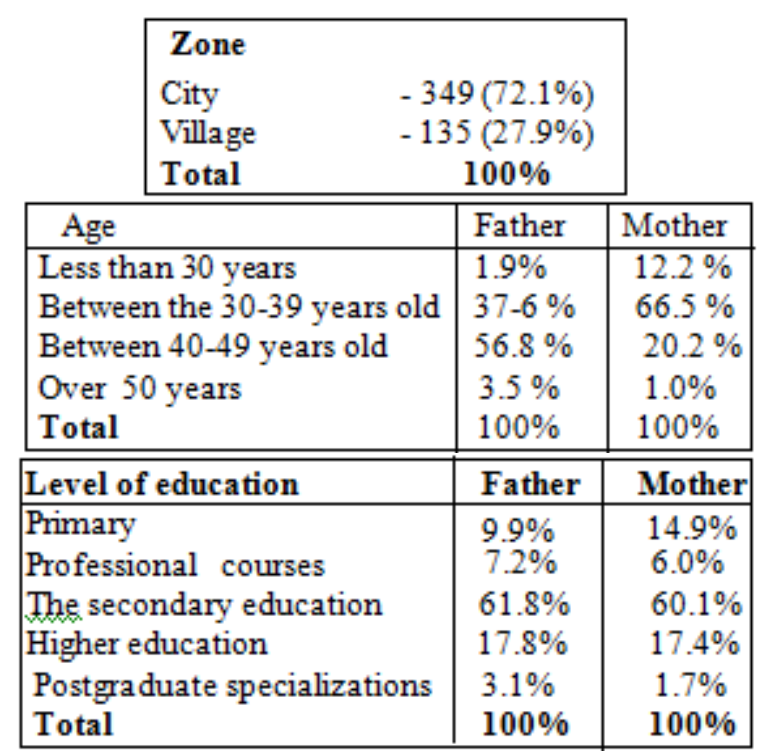

The family type that occurs today is characterized by 2 children (45.2\% of households) or 3 children (25.2\%), with a relatively young age, the average level of education and a married civil status (95.7\%). Analysis of parents' occupations shows a socio-economic level between low and average. There is a high level of household mothers (43.0\%). It's almost the same number of two parents who are looking for a job (around 11-12\% of them). The most common professions exercised by fathers are commercial / business activity (30.3\%) and employees or suppliers (32.2\%), while working mothers / sales (16.9\%) and teacher / clerk (10.7\%). Anthropometry data on 272 parents respond or $56 \%$ of parents.

Based on weight and height of reference, the calculation was made possible indicator of their body mass (BMI). Data analysis resulted in about $2 / 3$ of overweight fathers of whom $13.7 \%$ obese. Less concern for mothers presented data which $62.3 \%$ were normal, and 32.85 are overweight, of which only $5.3 \%$ appear obese.(Diagram 1.1). It would be more a correlation value of nutritional status of children in relation to that of their parents, but the lack of anthropometric data on $45 \%$ of parents made it impossible this information.

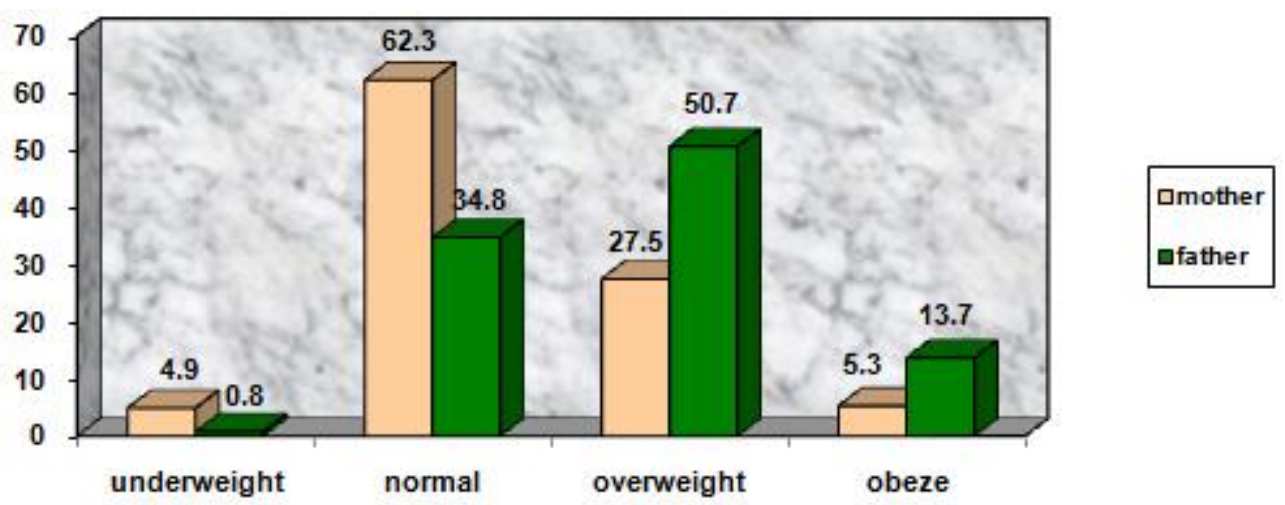

Diagram 1.1: The frequency of parents (\%) according to BMI's of autoreferuar.

There is a higher\% of overweight and obese children with mothers with higher education degrees (respectively 25\% and $3 \%$ ) compared to children of mothers with education
Postgraduate where the figures go respectively $12.5 \%$ and no child overweight children obese. (Diagram 1.2)

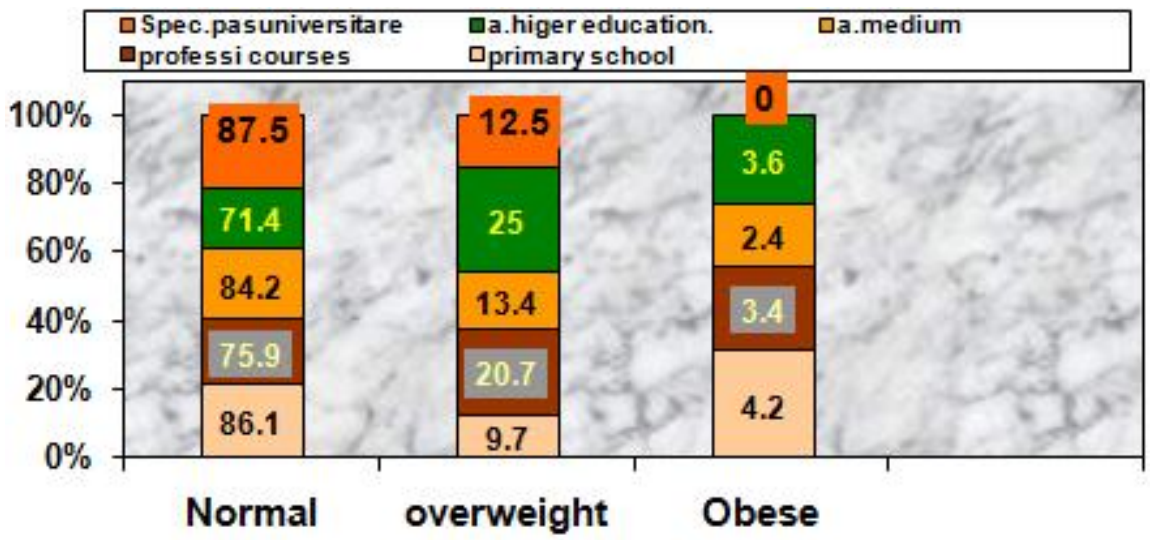

Diagram 1.2: Distribution of children's nutritional status by education level of the mother

Regarding the manner of feeding the child during the first year of life $94.6 \%$ of parents say that their child is breastfed, of whom about $83 \%$ are underweight- normal and $14.4 \%$ overweight, while there is a link-significant malnourished children obesity with breastfeeding ( $\mathrm{p}<0.05$ level) 


\section{International Journal of Science and Research (IJSR) \\ ISSN (Online): 2319-7064 \\ Index Copernicus Value (2013): 6.14 | Impact Factor (2015): 6.391}

Table. 1.2: Breastfeeding by nutritional status of children

\begin{tabular}{|c|c|c|c|c|}
\hline $\begin{array}{c}\text { Your child } \\
\text { is fed with } \\
\text { breast } \\
\text { milk }\end{array}$ & \multicolumn{3}{|c|}{ BMI of children } & \multirow{2}{*}{} \\
\cline { 2 - 5 } & Overweight & Obese & Normal & Total \\
\hline No & $66(\mathbf{1 4 . 4} \%)$ & $\begin{array}{c}12 \\
(2.6 \%)\end{array}$ & $\begin{array}{c}380 \\
(\mathbf{8 2 . 8 \% )})\end{array}$ & $458(100.0 \%)$ \\
\hline Yes & $8(30.8 \%)$ & $2(7.7 \%)$ & $16(61.5 \%)$ & $26(100.0 \%)$ \\
\hline Total & $74(15.3 \%)$ & $\begin{array}{c}14 \\
(2.9 \%)\end{array}$ & $\begin{array}{c}369 \\
(81.8 \%)\end{array}$ & $484100.0 \%)$ \\
\hline
\end{tabular}

$\mathrm{P}<0.05$

Another phenomenon is striking is the high number of children who do not eat breakfast (19.2\%) since the morning is one of the most important meals for children, through which they should provide around 20-25\% of their energy needs. Food on consumers during the morning are milk (82.8\%), egg sausage (80.2\%), fruits $(73.6 \%)$, fruit juice (71.6\%), bread and bakery products sweet (69.6\%), dairy butter (67\%). Most of the children associated with the morning water consumption (79\%). Regularly consume foods in school children $60.8 \%$, not $36 \%$ of them regularly.

Obese children often consume foods of overweight children in the evening and they normal ( $p<0.05$ level). (Diagram 1.3)

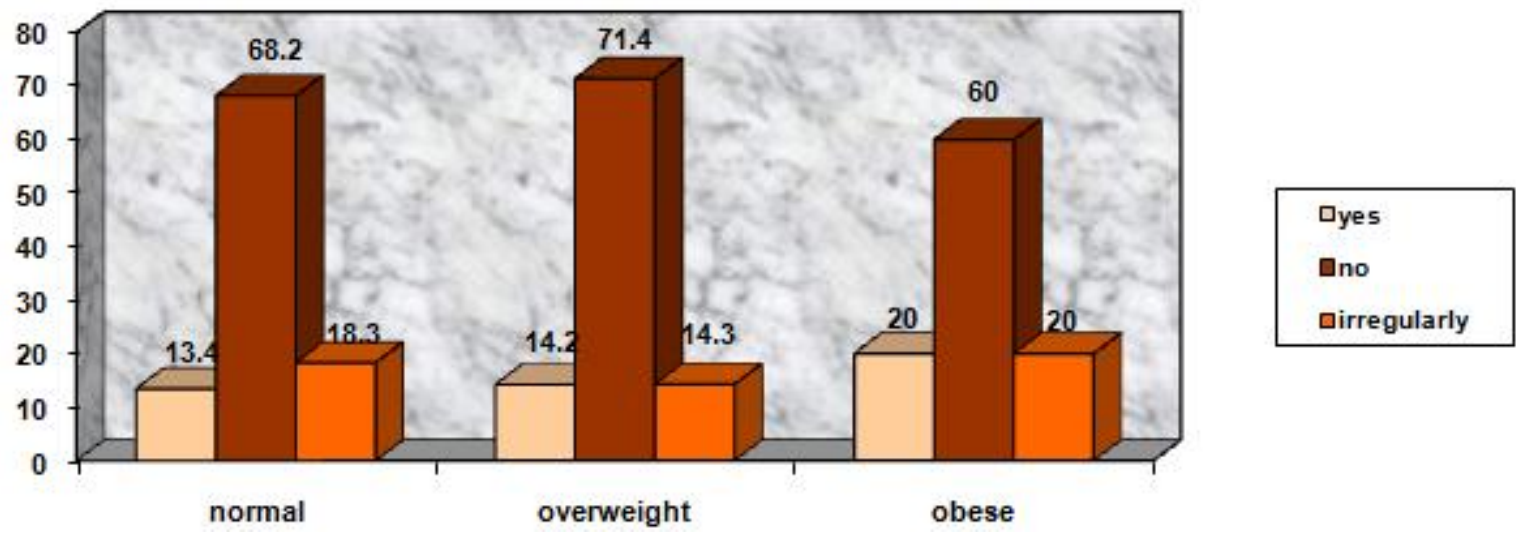

Diagram 1.3: The relationship between frequency in the evening children's consumption (\%) and their nutritional status. low intake, especially of fruits and vegetables, accompanied by a high level of preference for sweets (products rich in A deeper analysis became associated with the consumption of certain categories of food (diagram) where there was a fats and sugars ).

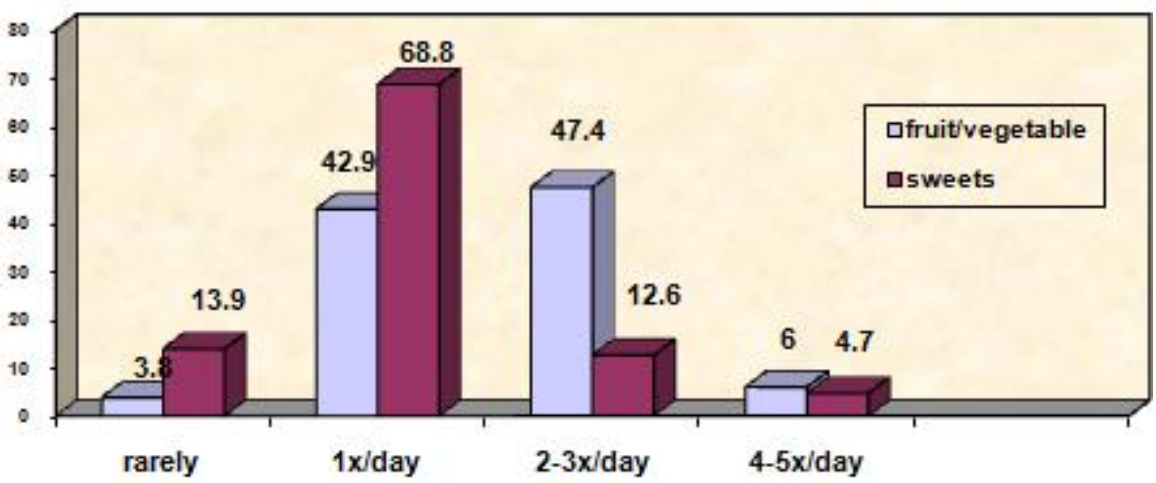

Diagram 1.4: Consumption of fruit / vegetables and sweets to children, declared by the parents

To prevent obesity in addition to a balanced nutrition is very important the establishment of a viable daily physical activity ${ }^{\{7\}}$ In our study a typical day in terms of the child's motor activity is calculated by asking parents to share their child's day according to time of holiday pay, learning and physical activity. (Diagram1.5). With easy task given the time that children spend on dining, reading, TV, personal hygiene, playstation, etc. On average activity including hiking, games, bicycle, aerobics, dance, etc. And finally intensive activity includes organized team sport.

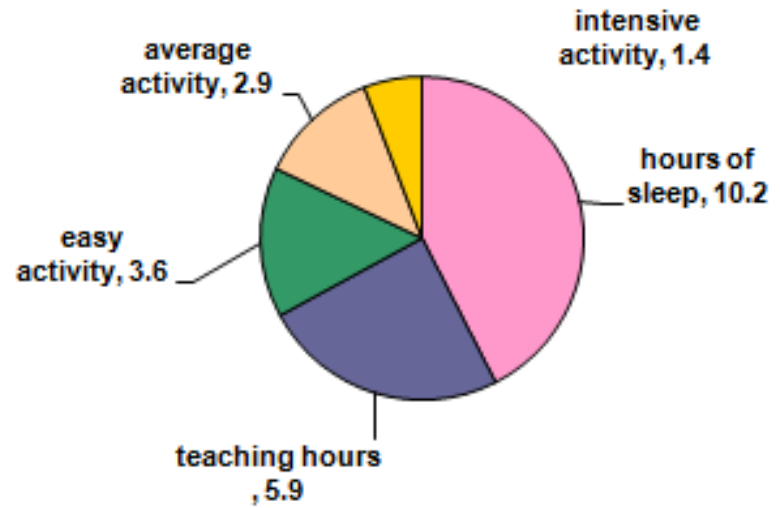

Diagram 1.5: Distribution of activity during the day for children 


\section{International Journal of Science and Research (IJSR) \\ ISSN (Online): 2319-7064 \\ Index Copernicus Value (2013): 6.14 | Impact Factor (2015): 6.391}

Increased sedentary lifestyle of children today is merit exposure in front of the television, computer or video games. So most children is on average 2 hours watching
TV, but noted that overweight and obese children using this tool for a long time ( $p<0.05$ level). (Diagram 1.6)

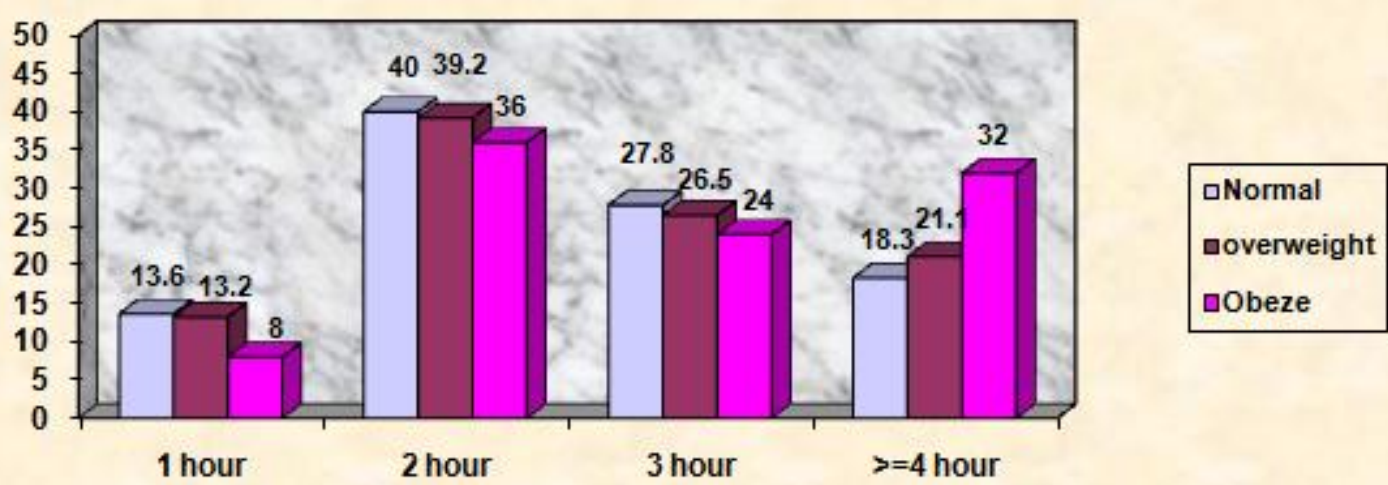

Diagram 1.6: The link between the nutritional situation of children and hours watching TV

Parents generally try to choose foods their children safe, high quality and fresh, healthy trying to comply with their wishes.

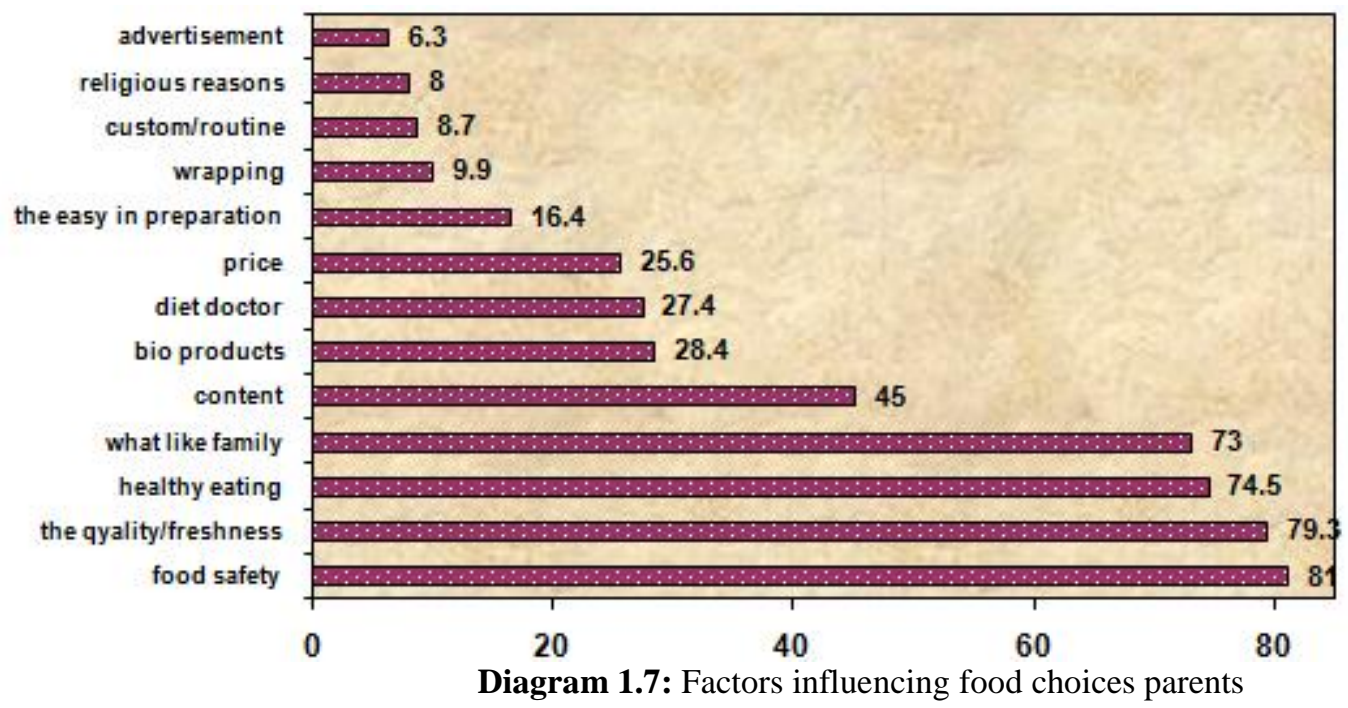

Dhave chosen \%

After the birth of a child, many parents tend to change the way of feeding the family in order to improve its adaptation and on his rearing function.

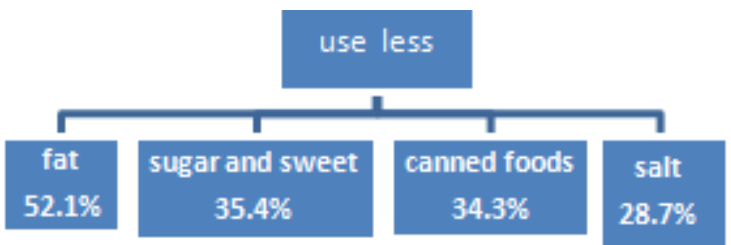

Diagram 1.8: Trends reduction of food consumption, after childbirth at home

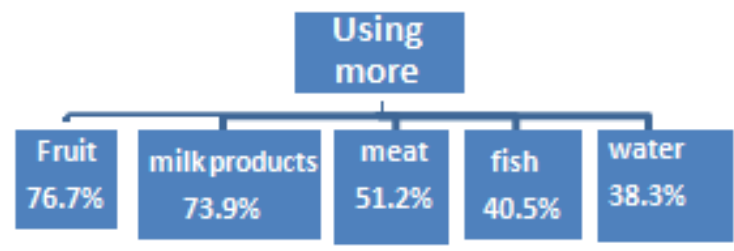

Diagram 1.9: Trends in food consumption growth, after the birth of the child

Parents do not hesitate to admit the difficulties for healthy eating. Thus the price of healthy food (41.5\%) is the obstacle most often followed by various preferences in the family (34.8\%), life too busy, less time for cooking (31.6\%), long time for preparation food (16.2\%), limited knowledge of healthy nutrition (11.6\%).

They do not lack sources of information on nutrition, ranging from television, books, friends, doctor, food labels, publicity to the school or consumer associations. However it remains to be seen how the quality of information and the position of these sources in terms of their primary role in informing and nutritional education.

For the preparation of food at home continues Albanian tradition of the primary role of the mother in this commitment. In $83.6 \%$ of cases it is what cooks in the family, followed by $8.8 \%$ grandmother, who to be $3.4 \%$, $2.8 \%$ siblings, and finally with a very modest commitment father found $0.6 \%$.

Parents give their judgment regarding body image of their child but do not hesitate to say that they would like to be a different image. Their preference is a trend towards a figure 


\section{International Journal of Science and Research (IJSR) \\ ISSN (Online): 2319-7064}

Index Copernicus Value (2013): 6.14 | Impact Factor (2015): 6.391

above that what the kids are really, otherwise the children what they wanted to be. (Table 1.3 and 1.4)

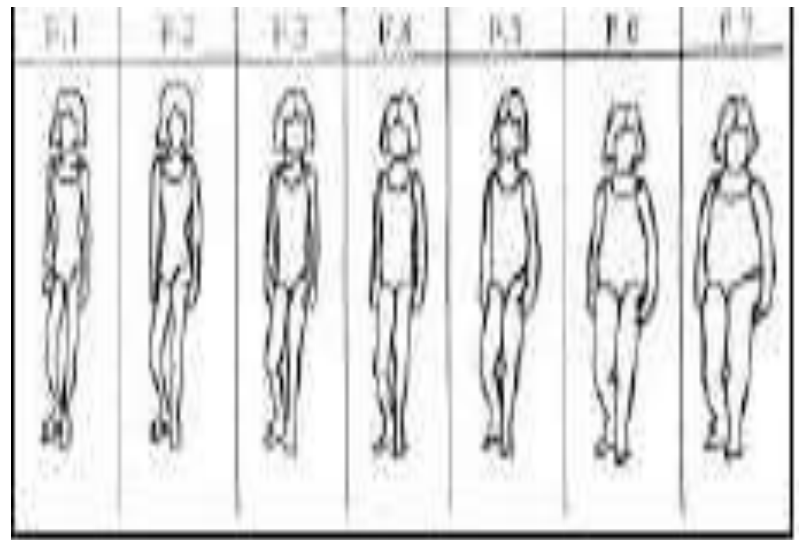

Table 1.3: Which of the figures is similar to your child

\begin{tabular}{|c|c|c|c|c|}
\hline $\begin{array}{c}\text { Picture } \\
\text { number }\end{array}$ & Frequency & $\begin{array}{c}\text { Frequency } \\
\%\end{array}$ & $\begin{array}{c}\text { Freq. } \\
\text { worth \% }\end{array}$ & $\begin{array}{c}\text { Freq. } \\
\text { Cumulative }\end{array}$ \\
\hline F1 & 6 & 1.2 & 1.2 & 1.2 \\
\hline F2 & 19 & 3.9 & 3.9 & 5.2 \\
\hline F3 & 58 & 12 & 12 & 17.2 \\
\hline F4 & 133 & 27.5 & 27.6 & 44.8 \\
\hline F5 & 153 & 31.6 & 31.7 & 76.6 \\
\hline F6 & 92 & 19 & 19.1 & 95.6 \\
\hline F7 & 21 & 4.3 & 4.4 & 100 \\
\hline Total & 482 & 99.6 & 100 & \\
\hline $\begin{array}{c}\text { Missing } \\
\text { data }\end{array}$ & 2 & 0.4 & & \\
\hline Total & 484 & 100 & & \\
\hline
\end{tabular}

Table 1.4: Which of the figures you would like your child to like

\begin{tabular}{|c|c|c|c|c|}
\hline $\begin{array}{c}\text { Picture } \\
\text { number }\end{array}$ & Frequency & $\begin{array}{c}\text { Frequency } \\
\%\end{array}$ & $\begin{array}{c}\text { Freq. } \\
\text { worth \% }\end{array}$ & $\begin{array}{c}\text { Freq. } \\
\text { cumulative }\end{array}$ \\
\hline F1 & 4 & 0.8 & 0.8 & 0.8 \\
\hline F2 & 20 & 4.1 & 4.1 & 5 \\
\hline F3 & 28 & 5.8 & 5.8 & 10.8 \\
\hline F4 & 131 & 27.1 & 27.2 & 38 \\
\hline F5 & 181 & 37.4 & 37.6 & 75.5 \\
\hline F6 & 94 & 19.4 & 19.5 & 95 \\
\hline F7 & 24 & 5 & 5 & 100 \\
\hline Total & 482 & 99.6 & 100 & \\
\hline $\begin{array}{c}\text { Missing } \\
\text { data }\end{array}$ & 2 & 0.4 & & \\
\hline Total & 484 & 100 & & \\
\hline
\end{tabular}

\section{Conclusion}

Nutritional situation of children affected directly by it's parents. Unlike the trend in Europe where children of parents with high education have a higher care to the problem of obesity, our study shows that children overweight or obese come Knowledgeable most from this category of parents, although the food choices they are guided by correct principles for a balanced nutrition. The exception is layered with Postgraduate education of mothers). Likewise, parents try to choose foods their children safe, high quality and fresh, healthy trying to comply with their wishes, using different information and tools for healthy eating for yourself and family them.

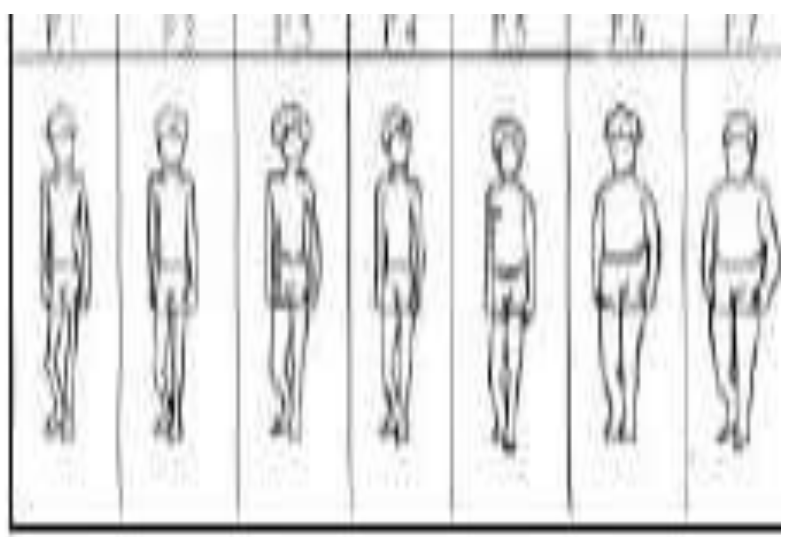

Parents have good knowledge in the field of nutrition and also want to be better informed. But despite possessing good knowledge, not in all families there is a healthy nutrition and activity of motor satisfactory. Of the most important tools that serve as a source of nutritional information for families, there is very little influence of the physician, school and consumer association in the promotion of knowledge in the field of nutrition. Noted the tendency of improving the method of feeding the family, the birth of a child, focusing it on reducing the consumption of fats, products sugary or containing preservatives and ngjyruesish, as well as reducing the consumption of salt trying to increase consumption of fruit, dairy, meat and fish.

Albanian families there are also difficulties for healthy eating. Thus the price of healthy food $(41.5 \%)$ is the obstacle most often followed by various preferences in the family (34.8\%), life too busy, less time for cooking (31.6\%), long time for preparation food (16.2\%), limited knowledge of healthy nutrition (11.6\%).

Learning models nutritional followed by children and their families (what they eat, where, when) allows you to develop appropriate support services for trading and distribution of food in schools, in relation to consumption more great food ready, found everywhere and are delicious. Nutritional habits, in fact, during childhood play a very important role not only for the direct impact on the welfare, growth and mental development, but also the impact on the state of adult health in the future.

\section{Recommendations}

Prevention is the best report cost-benefit for the control of overweight and obesity in developing age, and in the future, the adult age. Prevention can be achieved through various interventions that target: environment, physical activity and $\operatorname{diet}^{\{7\},\{8\}}$ Even in our country it is necessary to work on the network to prevent being obesity a multifactorial disease for which preventive interventions should be placed in all causal factors.

It is important:

- Increase the awareness and active involvement of parents, to enable the creation of lasting changes to the virtuous 


\section{International Journal of Science and Research (IJSR) \\ ISSN (Online): 2319-7064 \\ Index Copernicus Value (2013): 6.14 | Impact Factor (2015): 6.391}

life styles in order to increase the degree of efficiency of preventive interventions, to the fight against obesity.

- Setting up a network of interventions for schools to improve the quality nutrition in schools organized with food and distribute informational messages / mapping exercises to encourage, to children and their families, adopting a correct behavior towards food and physical activity;

- Use the weight of children reporting to parents to make them aware of the problem.

- Reducing the large volume of marketing of foods with high calories, beverages and fast food to children, particularly through the media and television, as Fast Food are the products that you become more advertisement on television, and children are often the market target their .

\section{References}

[1] De Onis M, Blossner M, Borghi E. Global prevalence and trends of overweight and obesity among preschool children. Am J Clin Nutr. 2010;92(5):1257-64.

[2] Wang Y, Lim H. The global childhood obesity epidemic and the association between socio-economic status and childhood obesity. Int Rev Psychiatry. 2012;24(3):176-88.

[3] Knai C, Lobstein T, Darmon N, Rutter H, McKee M. Socioeconomic patterning of childhood overweight status in Europe. Int J Environ Res Public Health. 2012;9(4):1472-89.

[4] Laitinen J, Power C, Jarvelin MR. Family social class, maternal body mass index, childhood body mass index, and age at menarche as predictors of adult obesity. Am J Clin Nutr. 2001;74(3):287-94.

[5] Shrewsbury V, Wardle J. Socioeconomic status and adiposity in childhood: a systematic review of crosssectional studies 1990-2005. Obesity (Silver Spring). 2008;16(2):275-84.

[6] Oh K, Jang MJ, Lee NY, Moon JS, Lee CG, Yoo MH, Kim YT: Prevalence and trends in obesity among Korean children and adolescents in 1997 and 2005. Korean J Pediatr 2008, 51:950-955.

[7] Sato AF, Jelalian E, Hart CN, Lloyd-Richardson EE, Mehlenbeck RS, Neill M, Wing RR: Associations between parent behavior and adolescent weight control. J Pediatr Psychol 2011, 36:451-460.

[8] Gibson LY, Byrne SM, Davis EA, Jacoby P, Zubrick SR: The role of family and maternal factors in childhood obesity. Med J Aust 2007, 186:591-595.

[9] Shrewsbury V, Wardle J: Socioeconomic status and adiposity in childhood: a systematic review of crosssectional studies 1990-2005. Obesity 2008, 16:275284.

[10] Hanson MD, Chen E: Socioeconomic status and health behaviors in adolescence: a review of the literature. J Behav Med 2007, 30:263-285.

[11] Kumanyika S, Jeffery RW, Morabia A, Ritenbaugh C, Antipatis VJ. Obesity prevention: the case for action. Int J Obes Relat Metab Disord 2002; 26: 425-436.

[12] Bronfenbrenner U. The Ecology of Human Development: Experiments by Nature and Design. Harvard University Press, 1979.
[13]Gibson LYBS, Davis EA, Blair E, Jacoby P, Zubrick SR. The role of family and maternal factors in childhood obesity. Med J Australia 2007; 186: 591595.

[14]Chen AY, Escarce JJ. Family structure and childhood obesity, Early Childhood Longitudinal Study Kindergarten Cohort. Prev Chronic Dis 2010; 7: A50. 